\title{
POR UM ENSINO QUE FORME PROFESSORES DE QUÍMICA PARA A MODALIDADE DE ENSINO DE JOVENS DE ADULTOS
}

\author{
Taline dos Ramos Lira, Universidade Federal de Campina Grande (UFCG), \\ talineramoslira@hotmail.com \\ Maria Thaize dos Ramos Lira, Universidade Federal Rural de Pernambuco (UFRPE), \\ thaize_ramosjp@hotmail.com \\ Geovana Vasconcelos Martins, Universidade Federal de Campina Grande (UFCG), \\ geovanavm@yahoo.com.br
}

\begin{abstract}
RESUMO
A Educação de Jovens e Adultos (EJA) é uma modalidade de ensino voltada para pessoas que não tiveram a oportunidade de frequentar e permanecer na escola no tempo devido. Para atender a esse novo perfil de educandos, o professor deve aliar a prática pedagógica tradicional e buscar diferentes ações que possam melhorar o ensino, de forma especial, aquelas que concretizem uma relação contínua entre conteúdos e o saber cotidiano. Sendo assim, este trabalho tem por objetivo analisar os componentes curriculares didático-pedagógicos do curso de licenciatura em Química da Universidade Federal de Campina Grande, campus de Cajazeiras, assim como o desenvolvimento dessa modalidade de ensino entre os alunos durante a sua formação. Para realização desse estudo, optamos por um estudo pormenorizado dos componentes curriculares e da ementa do curso. Através de um estudo sistemático da matriz curricular do referido curso, observou-se que essa instituição de ensino não apresenta nenhuma em seus componentes curriculares didático-pedagógicas e eletivas nenhuma formação complementar a respeito do trabalho com a EJA. Indicamos que é necessário repensar alguma alteração na matriz curricular do curso, que proporcione uma formação docente completa, para o profissional lidar de forma mais segura com essa modalidade de ensino.
\end{abstract}

PALAVRAS-CHAVE: EJA; Licenciatura em Química; Formação de Professores.

INTRODUÇÃO

A Educação de Jovens e adultos (EJA) é uma modalidade de educação que a Lei de Diretrizes e Bases (LDB) 9.394/96 assegura em seu artigo 37: “ a Educação de Jovens e Adultos será destinada àqueles que que não tiveram aceso ou continuada de estudos no ensino fundamental e médio na idade própria”. A EJA foi feita para a população que não finalizou o Ensino Fundamental ou Médio na idade almejada, seja porque não pode ingressar ou não 
conseguiu continuar na escola. A idade mínima de ingresso é de 15 anos para o nível fundamental e 18 anos para o ensino médio. Funciona, na maioria das escolas, no turno noturno, com 600 horas anuais, visando respeitar as peculiaridades da idade cronológica do educandos.

De acordo com os estudos de Mendes et al., (2010), a importância atribuída a EJA somente veio se apoiar na política nacional a partir de 1940, no qual o Estado Brasileiro ampliou os direitos sociais de cidadania. De fato, a intenção desse modelo de ensino pode ser considerada positiva: trazer novamente para a escola novas perspectivas de vida. Contudo, quando nos detemos para a prática, os objetivos se apresentam desviados, não vislumbramos os resultados esperados.

A partir dos apontamentos de Silva e Paulino (2009) a educação inclusiva está avançando, mas com muito esforço e resistência de algumas parcelas da sociedade. Isso se dá por vários fatores: ausência de estrutura nas escolas, o não preparo de docentes para atuarem diante das dificuldades que os discentes levam consigo para a sala de aula, que na maioria das vezes, vão desmotivados por problemas pessoais.

A Educação de Jovens e Adultos depende, como em todo modalidade de educação, de profissionais preparados, sem brechas em suas formações. Mas, na realidade educacional, não é isso o que acontece. Muitos profissionais no campo educacional atuam por algum por alguma necessidade financeira ou sem nenhuma dedicação ou dom para lecionarem. Nessa conjuntura, os docentes chegam, muitas vezes a assumir turmas da EJA sem nunc terem visto, na universidade, algo relacionado para a essa modalidade de ensino. Apesar esse questionamento deva ser discutido em qualquer curso de formação de professores das Instituições de Ensino Superior, sejam elas públicas ou privadas, este trabalho se volta para a realidade educacional do curso de Licenciatura em Química da UFCG?CFP.

Sendo assim, este estudo parte de uma inquietação pessoal, na qualidade de discente em formação, percebo que a grade curricular do curso de Licenciatura em Química não dispõe de componentes curriculares que enfatizam a EJA. O ensino de Química diz respeito á socialização de um conhecimento sistematizado, que se distingue de outros tipos de conhecimentos, a exemplo do senso comum.

O ensino de química deve abarcar assuntos relacionados a real necessidade humana, para a resolução de problemas, abordagem dos processos químicos industriais, medicinais e, além disso, o aprendizado na disciplina de química "deve possibilitar ao aluno a compreensão 
tanto dos processos químicos em si quanto da construção de um conhecimento científico em estreita relação com as aplicações tecnológicas e suas implicações ambientais, sociais, políticas e econômicas" (PCNEM, 1999, p.31).

Partindo dessa perspectiva e levando em conta que tais aspectos são vastamente discutidos para alterações no quadro da qualidade do ensino na educação básica regular, o que poderíamos esperar da modalidade de ensino EJA? Os conteúdos de química interessam os alunos da EJA? Que tipo de relação pode ser estabelecido entre os assuntos de química e o dia-a-dia? Como se dá a formação do professor de química para trabalhar com essa modalidade de ensino?

No que concerne ao ensino de Química, é importante que se consolide uma relação continuada entre os conteúdos e os saber do dia-a-dia. Ademais, por meio da abordagem cotidiana, o professor poderá estreitar a relação entre aquilo que é visto em sala de aula e aquilo que ele vivencia no seu cotidiano, possibilitando ao aluno um olhar mais harmônico para a química à sua volta.

Buscando atender os objetivos propostos, optamos pela pesquisa qualitativa, pois ela "compreende um conjunto de diferentes técnicas interpretativas que visam a descrever e descodificar os componentes de um sistema complexo de significados" (NEVES, 1996, p.1).

\section{FORMAÇÃO DE PROFESSORES PARA A EJA}

A prática educativa é um desafio constante, posto que o educador consciente do seu papel na sociedade, passa boa parte de seu tempo se questionando, reavaliando conceitos, buscando dar o seu melhor para os seus alunos, ou seja, o educador está sempre se capacitando.

A figura do professor poderia simbolicamente ser comparada com a de um maestro criativo que exigiria dos componentes da orquestra: organização, iniciativa própria, envolvimento, dedicação e, principalmente, ações coletivas desencadeadas por processos participativos. Sendo criativo, articulador, mediador e desafiador, o professor apostaria em todos os meios e recursos existentes para consolidar a construção do conhecimento (BEHRENS, 1996, p. 64).

Quando pensamos acerca da formação de professores para a EJA, a primeira questão que se coloca para quem exerce a profissão ou para quem pretende, é qual o motivo de se 
lecionar para jovens e adultos. Por quê? Provavelmente, em cada resposta obteremos uma vi são da educação, de forma especial de EJA, e também uma percepção de quem são os educandos, a importância da educação diante deles, do papel do docente. Uma reflexão que parece ser simples, banal, mas que ainda não esgotou a sua profundidade de reflexão.

Em sua maioria, os cursos de formação de professores preparam os profissionais para atuar com um aluno ideal, ou por que não dizer irreal? Aprendemos os assuntos das nossas áreas, passamos a conhecer algumas estratégias pedagógicas e metodológicas. Porém, estamos distantes de pensar a realidade efetiva da escola onde iremos atuar que seja por meio de concurso ou de forma temporária para a rede pública.

É possível encontrar nos documentos que regulamentam a formação dos licenciados nas mais variadas áreas do conhecimento, características profissionais que se pretende desenvolver no decorrer do curso de formação do professor. No tocante à licenciatura em Química, existe na esfera federal as Diretrizes Curriculares Nacionais para os Cursos de Química e as Diretrizes Nacionais para a Formação de Professores da Educação Básica, documentos que dão sustentáculo para os projetos pedagógicos do Brasil. Nesses termos e de acordo com Diretrizes Curriculares Nacionais para os Cursos de Química, o licenciado em Química deverá possuir uma formação generalista, sólida e com abrangência em diversos áreas da Química. Para além dessas prerrogativas, deverá possuir uma formação adequada para atuar como educador na Educação Fundamental e Média.

Seguindo os parâmetros, pesquisas apontam que a maioria dos cursos de licenciatura nas universidades negligenciam ou não oferecem componentes curriculares que abordem as especificidades da EJA. Os estudos de Moura (2006) elencam que a EJA não é encarada na perspectiva que os licenciados obtenham informações básicas sobre a sua existência. E acordo com esse cenário, o aluno não é instigado a se apropriar dos aspectos teóricos e práticos dessa modalidades. E, na grande maioria das vezes, saem da universidade sem conhecer as particularidades da Educação de Jovens e Adultos.

Uma das primeiras questões que se deve ter em mente é a de que a educação de crianças é diferente da de jovens e adultos. Não há como pensarmos no papel da educação para essa faixa etária, sem refletirmos sobre quem são esses sujeitos. Facilmente, podemos reconhecer que jovens e adultos não escolarizados advém de grupos sociais de baixo poder econômico. Alguns adultos provenientes do meio rural, jovens de bairros periféricos que frequentaram a escola às vezes com pouca assiduidade, sujeitos expulsos da escola, mulheres 
que já tem seus filhos crescidos, que quase ou nada tiveram acesso à escola. Pode-se ter ainda, àqueles alunos que são portadores de necessidades especiais e que por algum motivo foram deixados à margem do processo educacional, ou que são provenientes de escolas especiais, portadores de pequenas deficiências, enfim, uma vasta parcela de excluídos.

A Educação de Jovens e Adultos se efetiva em diferentes cenários. Os espaços são vários e na maioria das vezes precários, em escolas, empresas, templos religiosos, acampamentos rurais, apenas para citar os espaços mais corriqueiros. Dessa forma, no rol de características da EJA como uma modalidade de diversos contextos m que se efetiva a prática pedagógica e a pluralidade de seus sujeitos. Nos estudos de Oliveira (2004), podemos encontrar algumas reflexões acerca das marcas identitárias entre os educandos e educadores da EJA, que se refere a um encontro da desigualdade de oportunidades, da negação do direito à educação e à formação.

De fato, a história da EJA acontece, em grande medida, à margem da construção do Sistema de Escolar: com campanhas, movimentos sociais, ONGs, igrejas, sindicatos e voluntários... Contudo, sua análise sempre se fez em comparação com a modalidade de ensino normal.

Sabemos que a configuração em torno da EJA nem sempre foi como conhecemos hoje, os esforços da última década para uma reconfiguração do cenário da EJA tem possibilitado alterações no campo da formação de professores. Para tanto, podemos destacar dois movimentos importantes nesse viés: um mais direcionado aos órgãos oficiais de governo, com a participação importante do órgão normativo nacional em educação: o Conselho Nacional de Educação (CNE), que, por meio da Câmara de Educação Básica fixou, no ano de 2000, as diretrizes curriculares para a EJA e, outro, que provém da sociedade civil organizada em defesa da EJA, com ênfase para a participação dos fóruns de EJA e do Grupo de Trabalho de Educação de Jovens e Adultos, da Associação Nacional de Pós-Graduação e Pesquisa em Educação (Anped).

É de fundamental importância que conheçamos esses dois movimentos. O primeiro que teve como resultado as diretrizes para a EJA, iniciou-se por causa de vários conselhos estaduais de educação, que faziam consultas ao CNE sobre a maneira correta de interpretar os Art 37 e 38 da LDB (BRASIL, 1996), que versam acerca da Educação de Jovens e Adultos. Atendendo à solicitação, o Conselho optou pela consulta pública através de audiências para ouvir pesquisadores, responsáveis pelos sistemas públicos de ensino e organizações que 
atuavam na EJA para elaborar o debate. Esse processo teve como coordenador o professor Carlos Alberto Jamil Cury, que elaborou o Parecer e Minuta de Resolução das Diretrizes Curriculares para a EJA. Dentre todos os aspectos relevantes do Parecer CNE/CEB $\quad n^{\circ}$ 11/2000 aponta a necessidade da formação de professores para a EJA

Com maior razão, pode-se dizer que o preparo de um docente voltado para a EJA deve incluir, além das exigências formativas para todo e qualquer professor, aquelas relativas à complexidade diferencial desta modalidade de ensino. Assim esse profissional do magistério deve estar preparado para interagir empaticamente com esta parcela de estudantes e de estabelecer o exercício do diálogo. Jamais um professor aligeirado ou motivado apenas pela boa vontade ou por um voluntariado idealista e sim um docente que se nutra do geral e também das especificidades que a habilitação como formação sistemática requer (BRASIL, 2000, p. 56).

Nesses moldes, o Parecer é uma ferramenta que representa dispõe sobre os parâmetros norteadores para a EJA. Entretanto, não é raro encontrar muitos professores de EJA e muitos formadores de professores que ainda desconhecem e não veem, na prática, acontecer o que está estabelecido nesta resolução:

Art. 17 - A formação inicial e continuada de profissionais para a Educação de Jovens e Adultos terá como referência as diretrizes curriculares nacionais para o ensino fundamental e para o ensino médio e as diretrizes curriculares nacionais para a formação de professores, apoiada em:

I - ambiente institucional com organização adequada à proposta pedagógica; II - investigação dos problemas desta modalidade de educação, buscando oferecer soluções teoricamente fundamentadas e socialmente contextuadas; III - desenvolvimento de práticas educativas que correlacionem teoria e prática;

IV - utilização de métodos e técnicas que contemplem códigos e linguagens apropriados às situações específicas de aprendizagem (BRASIL, 2000).

Se prestarmos atenção no que prega o inciso IV, no que se refere à parte da situação "códigos e linguagens apropriados às situações específicas da aprendizagem", no caso dos profissionais formados pela atual grade curricular do curso de Licenciatura em Química, que não contam com nenhuma disciplina, nem obrigatória, nem eletiva acerca da EJA. Como esses professores atuam quando se deparam com essa modalidade de ensino? 
De acordo com Gatti (1997) o educador que trabalha com a EJA não tem formação adequada para atuar nessa realidade educacional e não tem recebido a devida atenção nos cursos de formação de professores. Muito pelo contrário, muitas vezes, tem sido deixada à margem, posto que os educadores que atuam na EJA estão distantes dos debates das políticas públicas situadas na questão das relações entre escola e sociedade.

Para superar uma formação fragmentada, tanto a instituição formadora de professores como os formadores e os futuros professores, precisam assumir que na "sociedade globalizada" se convive, simultaneamente, com a inovação e a incerteza. Por isso, a educação dos seres humanos se torna mais complexa, e a formação do professor, também, passa a assumir essa complexidade. Para superar a dicotomia entre ensino e pesquisa, teoria e prática, e possibilitar a construção de uma práxis dinamizada pela iniciativa, pelo envolvimento do futuro professor em projetos educativos próprios e fundamentados, torna-se necessário reconhecer tal complexidade (ENS, 2006, p.12-13).

O entendimento moderno do educador requer uma formação científica consistente, logicamente que, ligada a uma prática pedagógica crítica e consciente para discutir a atual condição da educação.

\begin{abstract}
Enquanto seres humanos conscientes, podemos descobrir como somos condicionados pela ideologia dominante. Podemos distanciar-nos da nossa época. Podemos aprender, portanto, como nos libertar através da luta política na sociedade. Podemos lutar para ser livres, precisamente porque sabemos que não somos livres! É por isso que podemos pensar na transformação (FREIRE E SHOR, 1986, p. 58).
\end{abstract}

Quando se trata de qualidade política, "a questão também é muito grave, porquanto, se a educação básica é instrumentação fundamental da cidadania, o professor não poderia ser agente dela, sem ser, ele mesmo cidadão" (DEMO, 1996, p. 87). E ainda acrescenta que "o professor deve ser imagem viva do aprender a aprender” (DEMO, 1996, p. 89). A alma do professor está numa busca constante pela aprendizagem, pensar, aprender a fazer para aprender a ser professor. A reflexão é um dos conceitos mais usados pelos estudiosos para se referir à formação de professores.

\title{
ALGUMAS CONSIDERAÇÕES
}

O que se espera dos profissionais da EJA é uma grande luta pela conquista do sistema escolar, apenas dessa forma que essa modalidade de ensino terá o direito ao conhecimento e a 
inserção que o mundo pós-moderno requer. Para que isso seja possível, os cursos de formação de professores devem desenvolver uma prática docente que se assemelhe com as características que ansiamos para o educador de EJA.

Ao levarmos em consideração que os jovens e adultos da EJA precisam, além de conhecimento científicos, práticas que possam utilizar a sua bagagem cultural a experiência acumulada, o ensino de Química na EJA não pode ser meramente preparatório para um exame de seleção. O ensino de Química deve propiciar que o aluno sejam letrados cientificamente para poderem atuar na sociedade e na comunidade onde vivem de forma expressiva. É preciso o ensino seja no contexto.

Sendo assim, é notório que a instituição de ensino superior, no caso, a UFCG, campus de Cajazeiras, precisa repensar a organização de uma grade curricular que facilite a formação de professores de Química para que estes possam, assim, contribuir para uma formação sólida, que possa atender as carências educacionais da EJA. Consideramos que, uma formação desejável seja o viés mais coerente para a construção de uma identidade profissional.

\title{
FOR A TEACHING THAT MAKES TEACHERS OF CHEMISTRY FOR THE MODALITY OF EDUCATION OF YOUNG ADULTS
}

\begin{abstract}
Youth and Adult Education (EJA) is a teaching modality for people who have not had the opportunity to attend and stay in school in due course. To meet this new profile of learners, the teacher must ally the traditional pedagogical practice and seek different actions that can improve teaching, especially those that materialize a continuous relationship between content and everyday knowledge. Thus, this work aims to analyze the didactic-pedagogical curricular components of the degree course in Chemistry of the Federal University of Campina Grande, Campus of Cajazeiras, as well as the development of this modality of teaching among the students during their formation. To carry out this study, we opted for a detailed study of the curricular components and the course menu. Through a systematic study of the curricular matrix of said course, it was observed that this educational institution does not present any in its didactic-pedagogical and elective curricular components no complementary training regarding the work with the EJA. We indicate that it is necessary to rethink some change in the curricular matrix of the course, which provides a complete teacher training, so that the professional can deal more safely with this teaching modality.
\end{abstract}

KEYWORDS: EJA; Chemistry graduation; Teacher training. 


\section{POR UNA ENSEÑANZA QUE FORME PROFESORES DE QUÍMICA PARA EL MODO DE ENSEÑANZA DE JÓVENES DE ADULTOS}

\section{RESUMEN}

La Educación de Jóvenes y Adultos (EJA) es una modalidad de enseñanza dirigida a personas que no tuvieron la oportunidad de asistir y permanecer en la escuela en el tiempo debido. Para atender a este nuevo perfil de educandos, el profesor debe aliar la práctica pedagógica tradicional y buscar diferentes acciones que puedan mejorar la enseñanza, de forma especial, aquellas que concreten una relación continua entre contenidos y el saber cotidiano. Por lo tanto, este trabajo tiene por objetivo analizar los componentes curriculares didáctico-pedagógicos del curso de licenciatura en Química de la Universidad Federal de Campina Grande, campus de Cajazeiras, así como el desarrollo de esa modalidad de enseñanza entre los alumnos durante su formación. Para realizar este estudio, optamos por un estudio detallado de los componentes curriculares y del menú del curso. A través de un estudio sistemático de la matriz curricular del referido curso, se observó que esa institución de enseñanza no presenta ninguna en sus componentes curriculares didáctico-pedagógicos y electivas ninguna formación complementaria respecto al trabajo con la EJA. Indicamos que es necesario repensar alguna alteración en la matriz curricular del curso, que proporcione una formación docente completa, para el profesional tratar de forma más segura con esa modalidad de enseñanza.

PALABRAS CLAVE: EJA; Licenciatura en Química; Formación de profesores.

\section{REFERÊNCIAS}

BEHRENS, Marilda Aparecida. Formação continuada de professores e a prática pedagógica. Curitiba: Champagnat, 1996.

BRASIL. Conselho Nacional de Educação. Câmara de Educação Básica. Parecer $\mathbf{n}^{\mathbf{0}}$ 11, de 10 de maio de 2000. Dispõe sobre as Diretrizes Curriculares Nacionais para a Educação de Jovens e Adultos. Disponível em: http://www.cne.gov.br. Acesso em: 26. Jul. 2017.

DEMO, Pedro. Questões para a teleeducação. Brasília: UNB, 1996.

ENS, Romilda Teodora. Significados da pesquisa segundo alunos e professores de um curso de Pedagogia. 2006, 138f. Tese (Doutorado em Educação: Psicologia da Educação)Pontifícia Universidade Católica de São Paulo. São Paulo, 2006.

FREIRE, Paulo e SHOR, Ira. Medo e ousadia: cotidiano do professor. Rio de Janeiro: Paz e Terra, 1986.

NEVES, José Luís. Pesquisa qualitativa: características, usos e possibilidades. Cadernos de pesquisas em administração, São Paulo: v. 1, n. 3. 1996.

OLIVEIRA, Edna Castro de. Sujeitos-professores da EJA: visões de si mesmos em diferentes contextos e práticas. Salto para o futuro. Set. 2004. Disponível em: 
http://cdnbi.tvescola.org.br/resources/VMSResources/contents/document/publicationsSeries/14278128 12481.pdf >. Acesso em 20. Ag. 2017.

SILVA, Claudia; PAULINO, Paulo Cesar. Capacitação inclusiva: dificuldades dos professores na EJA. In: III CURSO DE ESPECIALIZAÇÃO EM EDUCAÇÃO ROFISSIONAL INTEGRADA À EDUCAÇÃO BÁSICA NA MODALIDADE EDUCAÇÃO DE JOVENS E ADULTOS. Anais... Paraná: UTFPR Setembro, 2009. 